\title{
SOBRE EL ALMA: MATRIMONIO, CONFESIÓN Y CASUÍSTICA EN TORNO A EL BURLADOR DE SEVILLA
}

\author{
ELENA DEL RÍO PARRA \\ Georgia State University
}

A Rosario, ortodoxamente amiga.

Ya no pudo sufrir más la carnicería de su conciencia y se resolvió a librarse de aquel infierno portátil echándose un lazo al cuello (Cristóbal de Vega, Casos raros de la confesión).

\section{RESUMEN}

A lo largo de su interpretación crítica El burlador de Sevilla ha dado lugar a una serie de disquisiciones concernientes a la «gracia efectiva» y «gracia suficiente» para la salvación del pecador. Este artículo amplía los vínculos entre esta comedia y la literatura teológica de su época, concretamente la casuística confesional y matrimonial, para aproximarse a una nueva teoría del alma donjuanesca que la enclava en un contexto de irremisión insalvable.

Palabras clave: Casuística, alma, sacramentos, contrición, pecado.

\begin{abstract}
Along its critical interpretations, El burlador de Sevilla has given ground to a series of disquisitions that have to do with the concept of «effective» and «sufficient grace» for a sinner to be forgiven. The present article widens the links between the drama and theological writings of its time, especially confessional and matrimonial casuistry, in order to approach a new theory of the donjuanesque soul, which puts it in a context of insurmountable irremission.
\end{abstract}

Keywords: Casuistry, soul, sacraments, contrition, sin.

Sin duda una de las obras representadas en la España del Siglo de Oro de desenlace más espectacular fue El burlador de Sevilla y convidado de piedra de Tirso de Molina, cuya fecha de composición se cree anterior a 1625. A pesar de las muchas lagunas que rodean lo concerniente a la vida de fray Gabriel Téllez, es bien conocida la reprimenda que la Junta de reformación de costumbres le propina ese mismo año por «el escándalo que 
causa $[\ldots]$ con comedias que hace profanas y de malos incentivos y ejemplos», recomendando «al Nuncio le eche de aquí a uno de los monasterios más remotos de su Religión y le imponga excomunión mayor latee sententice para que no haga comedias ni otro ningún género de versos profanos» ${ }^{1}$. Este incidente dentro de su propia orden de los mercedarios no impidió la difusión de una comedia que escenificaba la reiterada trasgresión de valores morales, insolencia que encontraba un castigo ejemplar en el desenlace.

Uno de los grandes debates en torno a El burlador de Sevilla reside, precisamente, en lo nocivo de su representación, donde un pernicioso efecto secundario consistía en instruir en el engaño a doncellas y caballeros honestos. La evidente y pertinaz tensión a que don Juan somete la moral católica pone en entredicho los valores didácticos de esta comedia, que para muchos sobrepasaban su efecto catártico. Considerados en su contexto religioso, los llamados «dramas teológicos» de Tirso han tenido como centro de debate la consideración de la «gracia eficaz» para la salvación del alma, cuestionándose si el autor la ignora, la tiene en cuenta por un mero accidente histórico, la acepta expresamente o la rechaza de plano². Sin em-

\footnotetext{
${ }^{1}$ Críticos como Xavier A. FERNÁNDEZ ven una consecuencia directa entre la representación de la comedia y la reprimenda de la Junta (edic. de El burlador de Sevilla y convidado de piedra, Madrid, Alhambra, 1982). Los católicos incurren en excomunión latce sententice cuando el delito es de tal gravedad que no es necesario ser informados de ellos, actuando así como jueces de sí mismos y siendo efectiva la excomunión desde el momento mismo de la ofensa.

${ }^{2}$ Las opiniones oscilan desde «graves problemas teológicos» en torno a la disputa del molinismo que incluye una evolución de las posiciones teológicas de Tirso, perceptible en la dramaturgia (Jöel J. SAUGNIEUX, «Significación teológica, metafísica y psicoanalítica de "El burlador de Sevilla"», en Literatura y espiritualidad españolas, Madrid, Prensa española, 1974, p. 201), hasta lo que se consideran leves y casi inevitables referencias al asunto debidas al contexto histórico: «se ha pretendido reconocer las sutiles controversias sobre la predestinación y el libre albedrío surgidas en la estela del Concilio de Trento. Es un error. La doctrina de la obra carece de especial densidad teológica y no va más allá de las nociones de un catecismo elemental [...] que es intrínsecamente malo postergar la conversión [...] no obstante [...] es posible que la historia de Don Juan sí obedezca a ciertas orientaciones del Concilio» (Francisco Rico, «La salvación de Don Juan», en Breve biblioteca de autores españoles, Barcelona, Seix Barral, 1991, pp. 259-260). «La ruidosa cuestión de auxiliis aparecía de momento acallada, tras la imposición de silencio por Roma en 1607, pero seguía inquietando a muchos espíritus y no dejaba de hallarse muy presente en la conciencia colectiva de los españoles [...] Se comprende que Tirso cediera al peso intrínseco de la cuestión para toda conciencia religiosa de la época o hasta sintiera la necesidad de hacer su propia paz con la misma» (Francisco MÁRQuez VILlanueva, Orígenes y elaboración de «El burlador de Sevilla», Salamanca, Ediciones Universidad de Salamanca, 1996, p.132). Para los matices y diferencias entre molinismo, bañecianismo y zumelismo en la dramaturgia de Tirso, puede consultarse el estudio de José M. ${ }^{a}$ Delgado VARela: «Psicología y teología de la conversión en Tirso», en Tirso de Molina: ensayos sobre la biografía y la obra del padre maestro fray Gabriel Téllez, Madrid, Revista Estudios,
} 
bargo, considerada a la luz de la casuística — género moral por excelencia que, sin duda, Tirso conocía más o menos bien por sus estudios de teología ${ }^{3}$ - El burlador de Sevilla no depende sólo de un final correctivo para sustentar su didactismo postridentino. Más allá del papel de la gracia, nos interesa aquí la «microteología» expresada en los casos de conciencia planteados en esta gran obra de matrimonio y confesión. El análisis de estos dos temas a la luz de casos de conciencia y dudas morales apunta a un Tirso que emplea los entresijos de la casuística en la base de su obra y, lo que es más, dota a sus personajes del uso activo de la ciencia moral. Si, como afirmó Américo Castro, «para Tirso lo esencial en su obra era el aspecto teológico» ${ }^{4}$, es precisamente la teología del acuerdo matrimonial y la relación causa-efecto que para el alma tiene la formulación de un contrato falso ante Dios lo que nos interesa aquí, para considerar en qué convierte su comportamiento a Don Juan Tenorio desde la esfera del derecho canónico. Siguiendo la línea trazada por Francisco Márquez Villanueva ${ }^{5}$, podemos imaginar estos avatares humanos sin necesidad de abandonar los dominios de la teología porque la casuística no niega lo secular, sino que se empeña firmemente en considerarlo con pretensión legislativa e interventora.

En diversas culturas alrededor del mundo se han descrito numerosos tipos de matrimonio entre los que cabe enumerar algunos tan dispares como el simulado, solemne, solo ante testigos, tardío, asexual, de conveniencia, fiduciario, imposible, platónico, post mortem, en grupo, forzoso, de beneplácito, impuesto, oculto, perpetuo, indisoluble, plurimembre, fantasmal, clandestino, consuetudinario, temporal, a prueba, de incapaces, de menores de edad, por compra, por condena, por rapto, ilegal y de conciencia. La literatura casuística católica no llega a definir tanta variedad de contratos, pero sí matiza al máximo los que caen bajo su potestad reguladora, sujetos a un sinfín de avatares. El más básico consiste en definir quién está capa-

1949, pp. 360-362, así como los capítulos que Mario F. TRUBiano dedica a la génesis de esta polémica y a su posible influencia en el drama tirsiano (Libertad, gracia y destino en el teatro de Tirso de Molina, Madrid, Ediciones Alcalá, 1985).

${ }^{3}$ Ello es posible aun si fuese cierta la apreciación de Rafael M. ${ }^{\text {a }}$ de HorNEDO, quien ve en Tirso a un estudiante mediocre con conocimientos superficiales, que nunca fue maestro en Teología y que no reviste sus dramas teológicos de ninguna ideología particular en cuestiones de fe («La teología Zumeliana en el teatro de Tirso de Molina», en Estudios Eclesiásticos 24, 1950, pp. 217-236).

${ }^{4}$ Edic. de El vergonzoso en palacio. El burlador de Sevilla, Madrid, Espasa-Calpe, 1963, p. XXI.

5 «Tirso culmina de golpe la noción misma de un teatro religioso al añadir la nueva provincia del drama teológico [...] lo edificante será allí un legítimo problema humano, que se aborda como cualquier otro de carácter no religioso y que invita a ser discutido conforme a lo que es posible considerar como una incipiente «secularización» del mismo» (op. cit., p. 33). 
citado para recibir el sacramento del matrimonio, que no puede ser negado a tontos y bobos, carentes de juicio y considerados «como unas bestias y reses sin entendimiento ninguno», y aunque les es lícito tener descendencia como hizo el Rey de Francia, no parece muy honesto privarles de este beneficio $^{6}$. Algunos miembros de la Iglesia no son aptos para el matrimonio y debe negárseles. El Concilio de Trento señala específicamente a los vagos, quienes por su inestabilidad no son capaces de mantener una familia estable y tienden a la poligamia ${ }^{7}$ :

Muchos son los que andan vagando y no tienen mansión fija, y como son de perversas inclinaciones, desamparando la primera mujer, se casan en diversos lugares con otra, y muchas veces con varias, viviendo la primera. Deseando el santo Concilio poner remedio a este desorden, amonesta paternalmente a las personas a quienes toca, que no admitan fácilmente al Matrimonio esta especie de hombres vagos; y exhorta a los magistrados seculares a que los sujeten con severidad; mandando además a los párrocos, que no concurran a casarlos, si antes no hicieren exactas averiguaciones, y dando cuenta al Ordinario obtengan su licencia para hacerlo (cap. VII).

Si hemos de hacer caso a la estadística aportada por Helen Rawlings, la bigamia no era un problema acuciante a finales del siglo XVI: «[...] the number of bigamists brought before the tribunal of Toledo fell dramatically from 20 (1561-65) to 3 (1576-80)» ${ }^{8}$; pero en las sumas de casos de conciencia se impone una mentalidad previsora bajo la que se plantean situaciones de bigamia y poligamia descontrolada propiciadas por las interferencias entre el matrimonio y los votos, por confusiones entre la vida y la muerte o por «despistes» de los contrayentes. El matrimonio es uno de esos ámbitos en los que la casuística desarrolla su labor más subjetiva al calcular que cuando en el mundo no hubiese sino solo un padre y una hija se podrían casar a pesar del derecho natural y de la necesidad de dispensa9, y al exonerar de toda falta al hombre resucitado que no sabe si ha de volver con su mujer o puede casarse con otra ${ }^{10}$. La vuelta al estado seglar se plantea también

\footnotetext{
${ }^{6}$ Alonso de la Vega, Suma llamada silva y práctica del foro interior, Alcalá de Henares, Juan Íñiguez de Lequerica, 1594, lib. IV, casos 348 y 350.

${ }^{7}$ Recuérdese que estaba prohibida la entrada de vagabundos en América y, caso de lograr cruzar la frontera, debían trabajar o ser desterrados (Recopilación de Leyes de los Reinos de las Indias, Madrid, Julián de Paredes, 1681, pról. de Ramón MENÉndeZ Pidal, est. prel. de Juan MANZANo MANZANO, Madrid, Ediciones de la Cultura Hispánica, 1973, 4 t., ley 1, tít. 4, lib. 7, 283 y 284).

${ }^{8}$ Church, Religion and Society in Early Modern Spain, Hampshire y Nueva York, Palgrave, 2002.

9 Alonso de la VeGA, op. cit., lib. IV, caso 145.

10 «Un hombre casado pasó de esta vida y después de tres días quiso Dios tornarle a ella, si está obligado a volverse a su mujer y si vuelve, si ha de consentir de nuevo. Y si ha de casarse de nuevo, si será bígamo». Como hizo Lázaro, deben casarse de nuevo y no incurrirán en bigamia; y si no quieren, pueden casarse con quien deseen, ya que la muerte natural deshace el sacramento (Alonso de la VEGA, op. cit., lib. II,
} 
en el espacio conventual, donde los religiosos retornan del más allá o simplemente aspiran a una reincorporación a la vida secular sin incurrir en bigamia ${ }^{11}$. El mismo problema resulta de la reflexión de un casado que desea profesar en una orden religiosa, en cuyo caso no podrá hacerlo si su mujer está viva y el matrimonio ha sido consumado ${ }^{12}$. Otras preguntas recaen del lado de lo estrictamente secular, y consisten en variantes sobre matrimonios múltiples, con o sin conocimiento de los contrayentes, reflejando algunas una vida extremadamente complicada y de suyo «donjuanesca»: « $\mathrm{Si}$ será matrimonio el que uno hizo de esta suerte: que viviendo su mujer legítima se casó de hecho con otra segunda, y muerta ya su mujer primera y legítima se casó con otra tercera vez; estando así casado tuvo cópula con la segunda con quien se había casado antes, la cual ignoraba la muerte y matrimonio de la primera» ${ }^{13}$. Menor malicia y falsedad de intención indica una situación de completa ignorancia respecto al propio estado civil de una mujer que no sabe si su marido sigue vivo y contrae matrimonio con conciencia de viudedad. Tal circunstancia hace válido el sacramento de forma provisional, ya que si regresa el primer marido la mujer ha de volver con él y el segundo matrimonio será declarado nulo ${ }^{14}$.

Una de las regulaciones tridentinas mejor acogidas por la comunidad religiosa fue la condenación del llamado «matrimonio secreto» o «de conciencia» en 1563, un tipo de enlace que carecía de mediador eclesiástico y publicación previa, con un elevado número de recreaciones literarias y fuente de grandes conflictos sociales que reincidían en el abandono de la mujer secretamente desposada. El IV Concilio de Letrán (1215-1216) ya había

caso 472). Al mismo problema alude el caso 145 del tercer libro: «Si por alguna calamidad se viniesen a acabar los hombres, si a los religiosos y religiosas podrán constreñir a casarse, y si ellos en tal caso estaban obligados a obedecer».

${ }_{11}$ «Si un fraile lego profeso, u otro, sin estar ordenado muriese y después por milagro resucitase, si se puede lícitamente casar o si está obligado a volverse a la orden» (Alonso de la VEGA, op. cit., lib. IV, caso 183). «Si será bígamo el que siendo ordenado de orden sacro o teniendo hecho voto de castidad se casó». En este caso el clérigo secular puede apartarse de las órdenes con la única condición (disuasoria) de no consumar el matrimonio (Alonso de la VEGA, op. cit., lib. III, caso 168).

${ }_{12}$ Alonso de la VEGA, op. cit., lib. I, caso 121.

13 Alonso de la Vega, op. cit., lib. II, casos 523 y 524. Análogo enrevesamiento demuestra este otro caso: «Si Pedro dio palabra a María que muerta su mujer se casaría con ella sin haber tenido con ella ninguna cosa, después se casó con Juana y entonces tuvo acceso con María, si muerta Juana se puede casar con María» (Alonso de la VEGA, op. cit., lib. II, caso 531).

${ }^{14}$ «Si una mujer creyendo que su marido era muerto se casase segunda vez, y casada empezase a dudar si lo es o no, si puede pedir el débito conyugal al segundo marido con quien está casada» (Alonso de la VEGA, op. cit., lib. IV, caso 74). Una variante de este caso está en el celebérrimo juicio de Martin Guerre en 1560 recreado por Alejandro Dumas, donde la mujer viuda no está segura de si quien ha regresado es verdaderamente su esposo. 
prohibido las nupcias con parentesco hasta el cuarto grado y el matrimonio clandestino y en el Concilio de Trento, una vez tratado el asunto en la sesión XXIV, se restringió el parentesco al segundo grado dispensando a los grandes príncipes ${ }^{15}$ y mediante el decreto Tametsi («aunque») se declaró írritos los matrimonios clandestinos ocurridos a partir de ese momento, habiendo de celebrarse éstos en presencia de un párroco y de al menos dos testigos $^{16}$ so pena de excomunión, aboliendo explícitamente lo que se considera un pernicioso derecho consuetudinario «sin que obste privilegio alguno, o costumbre, aunque sea inmemorial, que con más razón debe llamarse corruptela» (cap. I). La supresión de hecho de esta práctica pretendía instituir una medida de control que dotaba a la Iglesia de la facultad exclusiva para legitimar las uniones, evitando de esa manera malentendidos y falsas promesas como las referidas más arriba:

De allí me fui deslizando poco a poco en la consideración de cuán santa, cuán justa y lícitamente había proveído el Santo Concilio de Trento sobre los matrimonios clandestinos. ¡Qué de cosas quedaron remediadas! ¡Qué de portillos tapados y paredes levantadas! Y cómo, si la justicia seglar hiciera hoy otro tanto en casos cual el mío, no hubiera el quinto ni el diezmo de las malas mujeres que hay perdidas. Porque real y verdaderamente, hablándola entre nosotros, no hay fuerza, sino grado. No es posible hacerla ningún hombre solo a una mujer, si ella no quiere otorgar con su voluntad. Y si quiere, ¿qué le piden a él? ${ }^{17}$.

De ese modo, la conciencia personal se transfiere enteramente a la jurisdicción clerical, que ha de hacer pública la decisión mediante las amonestaciones y seguir el ritual ortodoxo del matrimonio católico. Para conseguir el mismo fin se regulan otras formas de enlace que consideraban clandestinas tales como los raptos, que impedían la formalización de la pareja:

entre el raptor y la robada, por todo el tiempo que permanezca ésta en poder del raptor. Mas si separada de éste, y puesta en lugar seguro y libre, consintiere en tenerle por marido, téngala éste por mujer; quedando no obstante excomulgados de derecho, y perpetuamente infames, e incapaces de toda digni-

${ }^{15}$ Quintín ALDEA señala que uno de los mayores quebraderos de cabeza para la monarquía eran las dispensas matrimoniales. Había veintiséis causas de dispensa, llevando la vigésimo primera el título de sine causa, que se traducía en concederla por un elevado precio (Iglesia y Estado en la España del siglo XVII. (Ideario político-eclesiástico), Publicaciones anejas a «Miscelánea Comillas», Santander, Universidad Pontificia, 1961, pp. 123 y ss.).

${ }^{16}$ Éstos, además, tenían que estar despiertos, ya que dormidos no están presentes moralmente hablando, al igual que si estuvieran despiertos pero sin advertir para qué están allí, lo que invalidaría igualmente el matrimonio (Alonso de la VEGA, op. cit., lib. VI, caso 114).

17 Segunda parte de la vida de Guzmán de Alfarache. Atalaya de la vida humana [1604], edic. de José M. ${ }^{a}$ Micó, Madrid, Cátedra, 2001, t. 2, libro III, cap. II. 
dad, así el mismo raptor, como todos los que le aconsejaron, auxiliaron y favorecieron, y si fueren clérigos, sean depuestos del grado que tuvieren. Esté además obligado el raptor a dotar decentemente, a arbitrio del juez, la mujer robada, ora case con ella, ora no (Trento, cap. VI).

Antonio Escobar y Mendoza lista una serie de impedimentos dirimentes del matrimonio entre los que se incluyen, además del mencionado rapto, el error (cuando me dan a María pensando yo que había de ser Catalina); la condición (si soy libre y me caso con esclava creyendo que era libre, aunque no si yo soy esclavo y me caso con alguien que creo libre, porque no envilece mi calidad); el voto; el parentesco espiritual, legal o natural (pariente espiritual es el padrino de bautismo, legal es el adoptivo, y el natural se considera así tanto por línea recta como transversal); el crimen de homicidio o adulterio (si se mata al cónyuge para casarse, o si el adúltero promete que se casará, una vez muerto el cónyuge); disparidad de culto o religión; fuerza o violencia; orden sacro; ligamen (en matrimonio no consumado, ninguno puede contraerlo con otro); pública honestidad (si uno se casa de futuro, no puede contraer matrimonio con la madre, hermana ni hija de la futura cónyuge); afinidad; impotencia; y condición ${ }^{18}$.

Ninguno de los cuatro casos presentados en El burlador de Sevilla se acoge a impedimento dirimente $\mathrm{y}$, sin embargo, las maneras del amor cortés pasan de ser «un hecho de civilización superior» ${ }^{19}$ a sufrir la manipulación sistemática tanto por Don Juan como por las mujeres que se comprometen en esponsales ${ }^{20}$ dispuestas a cumplir el acuerdo. Éstos podían ser disueltos por múltiples razones, entre las que cabe contar el engaño y la malicia sugeridas en la propia comedia por un Don Juan conocedor de las leyes matrimoniales (vv. 2100-02) ${ }^{21}$. Otras muchas razones eran válidas para anular una palabra de matrimonio no consumado: si uno quedaba deforme, con enfermedad contagiosa, por tener la boca corrupta y con mal aliento ${ }^{22}$, por enemistarse, por la ausencia de uno de los contrayentes sin saberlo el otro, por pecado de fornicación de la mujer (aunque haya sido con violencia), por dejarse tocar impúdicamente la mujer, o si el varón tuviese mu-

${ }_{18}$ Examen y práctica de confesores y penitentes, en todas las materias de la teología moral, Valladolid, María de Quiñones, 1650, pp. 164-171.

${ }_{19}$ Paul BÉNICHOU, Morales du grand siècle, París, Gallimard, 1948, p. 53.

${ }^{20}$ Los esponsales, que constituían un contrato oneroso, eran la promesa de matrimonio futuro que intercambiaban las partes jurídicamente hábiles, en este caso los mismos contrayentes.

${ }^{21}$ Citamos siempre por la edición de Alfredo Rodríguez LóPEZ-VÁzquez, Madrid, Cátedra, 1996.

${ }_{22}$ Este es uno de los reproches de Mariana en el entremés cervantino El juez de los divorcios, donde el Procurador conoce el derecho eclesiástico: «Pues ley hay que dice, según he oído decir, que por sólo el mal olor de la boca se puede desc[as]ar la mujer del marido, y el marido de la mujer» (Ocho comedias y ocho entremeses nuevos nunca representados, Madrid, Viuda de Alonso Martín, 1615). 
chos ósculos y tactos con otra ${ }^{23}$. A pesar de estas circunstancias la palabra podía reclamarse años después, incluso habiendo habido otro matrimonio entre medias: «Si el que con juramento prometió a una doncella de casarse con ella y después se casó con otra, si muerta su mujer está obligado a cumplir el juramento a la primera» ${ }^{24}$.

La obra de Tirso de Molina, situada a caballo entre los universos anterior y posterior al Concilio, juega con la idea de un contrato vedado pero conocido por todos y practicado por muchos todavía en la primera mitad del siglo XVII, a pesar del feliz cerrojazo que el Guzmán pretendía dar al problema por esos mismos años. Su enclave en el siglo XIV salvaguarda la escenificación de crímenes contra la moral y los presenta como acontecimientos de un pasado remoto. Pero la presencia del matrimonio de conciencia en la casuística y la legislación moral posterior a Trento, por no hablar de su constante escenificación en los corrales de comedias, demuestra la preocupación por un asunto que, muy a pesar de la Iglesia, no conoce solución práctica. El matrimonio secreto se basa en la formulación de una promesa, de forma que

\begin{abstract}
el hombre que ha conocido deshonestamente a una doncella sin prometerle casamiento ni otra cosa alguna, ni la ha violentado para deshonestidad, no está obligado de ninguna manera a satisfacción alguna. Pero si hubo violencia o promesa, hay obligación a cumplir lo prometido y satisfacer todos los daños [...] Advierte Lesio que si un hombre de gran calidad o riquezas tuviese ocultamente alguna deshonestidad con una doncella muy desigual con palabra de casamiento, no quedará obligado el hombre a casarse. Porque estaba ella obligada a saber que estas palabras se dan fingidamente. Pero si la palabra se hubiese dado delante de otros se debe cumplir, porque no incurra en infamia la doncella ${ }^{25}$.
\end{abstract}

Por un lado, esta declaración exime a Don Juan de su obligación para con Tisbea y Aminta, y hace recaer la culpa en unas mujeres desiguales en clase $^{26}$, aunque no en su honor de cristianas viejas del siglo XIV, que actúan atraídas por la condición social del caballero y tienen la responsabilidad de saber que un noble no cuenta con motivos que le compensen el

${ }^{23}$ Pablo RAmón, Cartilla y explicación de los rudimentos de la Teología moral, Madrid, Imprenta Real, 1688, p. 134.

${ }^{24}$ Alonso de la VEGA, op. cit., lib. VI, caso 125.

${ }^{25}$ Juan EnRíQueZ, Cuestiones prácticas de casos morales, Córdoba, Salvador de Cea Tesa, 1646, pp. 41v-42r.

${ }^{26}$ Puede alegarse un agravante en el caso de la pescadora, quien declara haber hecho voto de castidad (vv. 406 y ss.) y se lo oculta a Don Juan teniendo obligación de decírselo bajo pena de pecado mortal (Manuel Filguera, Suma de casos de conciencia que se disputan en la Teología moral [...] Tomo segundo, en que se trata todo lo perteneciente a las materias de Conciencia, Pecados, Leyes, Preceptos del Decálogo y de la Iglesia, Madrid, Melchor Álvarez, 1686, p. 326). La misma Tisbea se declara «desigual» a Don Juan (v. 930). 
desposorio. Por otra parte, aunque sin testigos, se ha dado juramento verbal en cada ocasión, lo cual obliga a cumplir lo acordado, pero en la promesa de matrimonio es clave el propósito de los contrayentes, entendido éste como dominio del fuero interior, de modo que «el que prometió sin intención casarse para estar con una mujer y luego no cumple la promesa no contrae esponsalias porque no hizo promesa de matrimonio futuro $»^{27}$. Los personajes que tienen acceso al fuero interno de Don Juan, sobre todo su criado, saben de estos juramentos en vano que pesan sobre el consentimiento de las doncellas aunque éstas accedan y admitan posteriormente su culpa sin «disculpa que la venza» (vv. 187-88), sufriéndolo especialmente las más jóvenes,

\begin{abstract}
porque si ellas llegaran a conocer lo mucho que perdían en esto [...] primero se dejarían matar que hacer cosa semejante. Y así los que con poco temor de Dios y de sus conciencias, atendiendo solamente a sus deleites carnales desfloran a alguna doncella de poca edad [...] o con fraude o con violencia quedan obligados a resarcir el daño que les hacen o casándose con ellas, que es lo más acepto y agradable a Dios, o ayudándolas a que se casen bien ${ }^{28}$.
\end{abstract}

Una solución facilitada por la autoridad civil en las tres jornadas de $E l$ burlador de Sevilla es el matrimonio impuesto para llevar a término «buenos casamientos», uso perfectamente válido y aprobado por la Iglesia incluso en casos extremos como la amenaza de muerte o el interés vital ${ }^{29}$. Para Doña Ana esa imposición es doble, al ser prometida a Don Juan y más tarde a Octavio pero, descontenta por la elección matrimonial del rey en connivencia con su padre, pretende adelantársele por medio de una cita con su primo el Marqués de la Mota, transgrediendo las limitaciones de consanguinidad sin dispensa eclesiástica ${ }^{30}$. Como indica la situación de Doña

${ }^{27}$ Pablo RAmón, op. cit., p. 132. Precisamente por ello, no será matrimonio «el que hizo Pedro, que pensando que se casaba con Juana se casó con María, con la cual si lo supiera se holgara de ello, pero con todo eso pensó que era Juana y no María». Si luego Pedro decide quedarse con María tiene que volver a casarse (Alonso de la VEGA, op. cit., lib. IV, caso 130). Esta «reserva mental» no es exclusiva de la educación jesuítica, como parte de la crítica ha supuesto, haciendo a Don Juan estudiante de esta orden: «On the question of a reference to casuistry, it is probably more fruitful to consider the dramatist's motives than Don Juan's» (Daniel RogERS, «Fearful Symmetry: The Ending of El burlador de Sevilla», en Bulletin of Hispanic Studies 41, 1964, p. 148, n. 2).

28 Manuel Filguera, op. cit., p. 324.

29 «Si será matrimonio el que uno hizo de su propia voluntad porque no le matasen» (Alonso de la VEGA, op. cit., lib. II, caso 207), y «Si será matrimonio el que uno hizo con una hija de un médico sólo porque le curase viéndose en el artículo de la muerte y temiendo de morir si no le curaba». El matrimonio es válido porque el miedo lo impide, pero como nace de la enfermedad y no del médico, éste puede pedir como retribución que el paciente se case con su hija (Alonso de la VEGA, op. cit., lib. II, caso 281).

30 Tanto Doña Ana como el Marqués saben que son primos, pero ese no es siempre el caso. La casuística indica que uno tiene obligación «de avisar a su prójimo de que 
Ana, el matrimonio concertado, como el secreto, conlleva el riesgo de convertir a las hijas en mercancía de interés, de lo que advierte el Concilio de Trento en su capítulo IX:

\begin{abstract}
Llegan a cegar muchísimas veces en tanto grado la codicia, y otros afectos terrenos los ojos del alma a los señores temporales y magistrados, que fuerzan con amenazas y penas a los hombres y mujeres que viven bajo su jurisdicción, en especial a los ricos, o que esperan grandes herencias, para que contraigan matrimonio, aunque repugnantes, con las personas que los mismos señores o magistrados les señalan. Por tanto, siendo en extremo detestable tiranizar la libertad del matrimonio, y que provengan las injurias de los mismos de quienes se espera la justicia; manda el santo Concilio a todos, de cualquier grado, dignidad y condición que sean, so pena de excomunión, en que han de incurrir ipso facto, que de ningún modo violenten directa ni indirectamente a sus súbditos, ni a otros ningunos, en términos de que dejen de contraer con toda libertad sus matrimonios.
\end{abstract}

La ruptura de un matrimonio secreto requiere de una compensación civil en forma de boda, y espiritual en forma de confesión y penitencia. La Iglesia pone a disposición de los creyentes católicos los medios necesarios para la curación y salvación del alma, independientemente del pecado cometido y del castigo secular que corresponda. La confesión se establece así como el mejor modo de terapia y está, como el matrimonio, regulada hasta el más nimio detalle. Aunque los cauces de la literatura confesional han generado una historia crítica que excede los límites de este estudio ${ }^{31}$, la casuística entrevera ocasiones de duda en este momento clave para el alma y las incluye entre los problemas de conciencia listados en las sumas y, de igual modo, los confesionarios incluyen casos dudosos entre sus materiales pedagógicos.

La penitencia se compone de contrición, confesión y satisfacción, esto es, la confesión es la segunda fase de una compensación, de modo que si falta la contrición ésta no tiene sentido, a menos que el individuo pierda la consciencia: «Un hombre que haya vivido desastradamente, y llegando el artículo de muerte se halla sin sentido ni muestra de contrición puede ser absuelto bajo condición, ya que por el solo hecho de ser cristiano pide a

María, con quien está casado o con quien se quiere casar, es su parienta o que no es su mujer, lo cual él ignora», con la esperanza de que evite el error (Alonso de la VEGA, op. cit., lib. IV, caso 113).

31 Los manuales de confesión medievales habían sufrido una transformación paralela a la que vieron las sumas de casos de conciencia, haciéndose más breves y prácticos para facilitar la aplicación de las normas canónicas vigentes. Los sacerdotes postridentinos estaban especialmente bien instruidos en el «arte de confesar» gracias a una multitud de confesionarios que forman un panorama bibliográfico plagado de «tratados», «interrogatorios», «remedios» y «memoriales» que reúnen las normas y habilidades para formar perfectos confesores y penitentes, despuntando especialistas en este género como Bartolomé Talayero. 
Dios misericordia» ${ }^{32}$. De la misma opinión es fray Alonso de la Vega, quien admite que «por solo amor de Dios amándole super omnia se perdonan los pecados», pero que ha de haber retractación de éstos: «es menester para que este amor de Dios super omnia perdone los pecados mortales olvidados que primero, como está dicho, se haga diligente inquisición de ellos» ${ }^{33}$. Como explica más por extenso fray Juan Enríquez,

Si puede ser absuelto el hombre que pidió confesión y cuando el confesor llegó ya había perdido el sentido, pero no espirado: Algunos doctores afirman que de ninguna manera puede un confesor absolver a un hombre que pidió confesión y cuando el confesor llegó había ya perdido el sentido; y así, ni de palabra ni por señas pudo confesar algún pecado; y la razón que dan es decir que, aunque es verdad que pidiendo el hombre confesión dice ya con esto algún pecado en género pero no basta para ser absuelto, sino que es menester decirlo en especie.

Otros doctores se adelantan otro poco más y dicen que puede el confesor en este caso absolver debajo de condición [...] Pero no obstante esto, digo, que cuando un hombre está acabando pidió confesión y cuando el confesor llegó ya había perdido el sentido pero no había espirado, cuando un hombre que está con sentido muriéndose y no puede hablar, ni puede por señas explicar algún pecado pero da señales de dolor puede en estos casos ser absuelto sin condición alguna [...] De modo que se dice aquí que, pidiendo un hombre confesión, y cuando el confesor llega no puede hablar, que constándole al confesor de que pidió confesión, lo absuelva [...] Y así es mucho de admirar que estando todo esto tan expresamente determinado por el Concilio Cartaginense, que haya habido doctores que tan expresamente hayan afirmado lo contrario.

Y la razón que dan de que no basta para la confesión decir el pecado en género, sino que es menester decirlo en especie. Respondo que todo esto es verdad cuando el hombre puede decir su pecado en especie. Pero no pudiéndolo decir en especie, sino del modo que puede, cual es pidiendo confesión o diciendo al confesor por señas que se quiere confesar mostrando dolor de haber pecado ya aquí dice su pecado en género, porque no lo puede decir en especie $^{34}$.

Para hacer válidas estas circunstancias excepcionales es necesario que esté presente el confesor ${ }^{35}$, hecho que no siempre acontece, pero en la mayoría

${ }^{32}$ Manuel Pérez, Farol indiano, y guía de curas de indios. Suma de los cinco sacramentos que administran los ministros evangélicos en esta América. Con todos los casos morales que suceden entre indios, deducidos de los más clásicos autores, y amoldados a las costumbres, y privilegios de los naturales, México, Francisco de Rivera Calderón, 1713, p. 47.

${ }^{33}$ Op. cit., lib. I, caso 21

${ }^{34}$ Op. cit., pp. 96r-96v.

${ }^{35}$ Don Juan reconoce a Don Pedro la comisión de un acto delictivo, pero ello no se traduce en confesión eclesiástica, que requiere de otros protocolos. Curiosamente, en las ejecuciones era práctica obligada que el verdugo pidiese al reo perdón antes de acabar con su vida, en una absolución del condenado a su ejecutor, que haría las veces de pecador ante el confesor en una inversión de roles. Si el verdugo no obtenía la deseada clemencia, se cebaba en el castigo con métodos que hicieran sufrir más al reo. 
de los casos la Iglesia espera la contrición del fiel, acto que sólo puede excusarse si uno ha olvidado los pecados ${ }^{36}$. Para evitar este riesgo, los desmemoriados están obligados a apuntarlos para confesarlos a su tiempo ${ }^{37}$ y todo fiel ha de hacer un esfuerzo por recordar sus pecados, ya que ha de confesarlos todos y sólo en muy pocos casos pueden omitirse. Se recomienda callar pecados cuando de su confesión se siguiera «grave daño al alma, al cuerpo o a la fama [...] porque la ley natural es primero que la divina $\star^{38}$, y también hay dispensa para algunos pecados mortales si el confesor ha de permanecer alejado por riesgo de contagio en tiempo de peste ${ }^{39}$, si el hombre que se está confesando muere de repente, cuando hay una gran tempestad en el mar con peligro de ahogarse o cuando se está peleando en la guerra, en cuyo caso se puede administrar una absolución general ${ }^{40}$.

Es de vital importancia declarar el tiempo y número de los pecados y saber cuántos se han consumado, cuestión que no siempre está clara. Comete pecados distintos el que «con un tiro mata dos clérigos [...] lo mismo digo de la delectación morosa: que si se excita a ella con más de un objeto, tantos pecados comete como fueron los objetos» ${ }^{41}$, pero es importante considerar si la materia es contable o incontable, por lo cual «el que jura o promete castidad cien veces sólo un pecado mortal comete no cumpliendo, porque la materia es una siempre. Pero si jurare de dar de palos veinte veces a un hombre haría veinte pecados mortales, porque aquí la materia ofrecida es prohibida con precepto negativo, y vale por veinte ${ }^{42}$. Juan de Cárdenas y Mendieta reconoce que la excesiva prolijidad no atiende al beneficio del penitente, especialmente en lo que se refiere a la duración de los pecados de pensamiento, y si tuviera

\footnotetext{
${ }^{36}$ Alonso de la VEGA, op. cit., lib. I, caso 22.

${ }^{37}$ Alonso de la VEGA, op. cit., lib. III, caso 77.

${ }^{38}$ Manuel PÉREZ, op. cit., p. 72.

${ }^{39}$ El Obispo también puede ausentarse en tiempo de peste, según Pedro de LEdesma, Primera parte de la Suma, en la cual se cifra y suma todo lo que toca y pertenece a los sacramentos [...] principalmente lo que toca y pertenece al sacramento de la confesión [...] y todo lo que pertenece a las censuras eclesiásticas, Salamanca, Antonia Ramírez, 1614, p. 31, col. 1.

${ }^{40}$ Juan ENRíQUEZ, op. cit., pp. 95r-95v.

${ }^{41}$ Anselmo GómEZ, Tesoro de la ciencia moral y suplemento de las sumas más selectas y modernas que hasta ahora han salido [...] Van añadidas al fin las proposiciones de nuestro Santísimo Padre Alejandro VII expedidas el año de 1666, Valladolid, María de Pereda, 1668, pp. 42r-42v.

${ }^{42}$ Simón de Salazar y Juan Anastasio de Arana, Súmulas de moral, e índice de vocablos: primera, y segunda parte [...] y los preámbulos, advertencias, e Índice de Vocablos del R. P. M. Fr. Anastasio de Arana [...] Van al fin un Destierro de ignorancias y desengaño para todo género de personas y un Decreto de Inocencio XI [...] Obra importantísima para exámenes de órdenes, beneficios y de confesar, y en especial para principiantes, aunque no hayan oído artes, Madrid, Andrés García de la Iglesia, [1679?],
} p. 80 . 
obligación a confesar las circunstancias agravantes se hiciera molesta la confesión y se siguiera una ansiedad y escrúpulo continuo en los penitentes sobre si habían o no explicado bien las tales circunstancias, especialmente la del tiempo especialmente en los pecados de pensamiento, $v$. g., si el ánimo de hurtar, si duró una o dos horas, y lo mismo en materias venéreas y en materias de odio y mala voluntad al prójimo, que era menester andar con reloj para saber si permaneció una hora o un cuarto más ${ }^{43}$.

A Don Juan le está vedada la confesión desde el propio derecho canónico, que es muy claro en sus términos en el punto referido a la oportunidad de restitución y que niega la confesión al fiel si no satisface el daño, pudiéndolo hacer, «porque está claro que no hizo el entero examen de la conciencia, y a esta causa es inválida la confesión [...] Hecho este tal examen, si hallare ser obligado a satisfacer a algún prójimo el agravio que le hizo, en la fama o en la honra o hacienda o en el alma, escandalizándole, trabaje cuanto pudiere, si fuese posible, de satisfacerle enteramente o en parte antes de llegar a confesarse ${ }^{44}$. De este modo, la concesión de una oportunidad final de confesión no depende tanto de la eficacia de la gracia como de los mecanismos de expiación, que requieren de la diligencia del fiel para evitar situaciones de riesgo. Don Juan ha cometido varios pecados mortales, a saber: dos de falsas promesas, dos de suplantación, otro de temeridad, otro de juramento en vano $^{45}$, otro de soberbia, otro de vanagloria ${ }^{46}$, otro de burla a la religión, y otro contra la propia fe. Pero su actitud denota que sólo se molesta en llevar la cuenta de sus deudas para jactarse de ellas, y que no pretende corregir su pertinacia ni restituir el daño (conflicto aparte es con quién tendría que haberse casado de no haberse producido tal desenlace).

Sorprende la ausencia a lo largo de la obra de un sacerdote que trate de evitar estos crímenes contra la religión, cuya presencia habría facilitado la mediación. Catalinón, el interlocutor más cercano a Don Juan, evita arriesgar su empleo y, consciente de la imposición de penas a los cómplices (vv. 2002-05), se resguarda en las acciones clasificadas como «indiferentes», anula su voluntad a partir de la reprimenda de su señor y está dispuesto a dejar de ser la voz de aviso e incluso a poner manos violentas en el clero (vv. 1370-73):

\footnotetext{
${ }^{43}$ Compendio moral de los sacramentos en común y en especie particular con algunas resoluciones morales, Biblioteca de la Universidad de Sevilla, ms. 331-086, cuestión IV, §II.

${ }^{44}$ Alonso de VASCONES, Destierro de ignorancias y aviso de penitentes [...] y pictima del alma y arte de ayudar a bien morir, Madrid, Imprenta Real, 1663, p. 58.

${ }_{45}$ Jura en vano por Dios para conseguir a Aminta (v. 2090).

46 «El que se jacta o gloria de haber pecado, si está obligado a confesar la especie de tal pecado»: "porque sólo se atiene a las vanaglorias de sus malos hechos, séase en la materia que fuere [...] si no hay vanagloria, sino simple relación del hecho, como la destreza con que hizo un hurto, no es pecado mortal» (Anselmo GómEZ, op. cit., p. 45r).
} 


\begin{abstract}
¿Cómo se ha de haber con los medianeros, terceros o alcahuetes? Hay cosas intrínsecamente malas, como hacer espaldas para matar a los amigos de la mujer a quien se pretende, e indiferentes como guardar y defender la persona de quien se acompaña; llevar cartas claramente deshonestas, que se conoce el pecado mortal, es intrínsecamente malo; llevarlas para que venga la amiga es indiferente, pues puede venir a otra cosa $[. .$.$] ¿Qué acciones indiferentes son$ esas a una mano, que son lícitas a los criados? Aparejar el caballo en que ha de ir el amo a casa de la amiga, hacerle espaldas para guardarle, poner a la amiga la mesa, guisar la comida, llevarla a casa, llevarle papeles no deshonestos aunque sí de alguna afición y más que ordinaria cortesía, ministrar regalos, abrir puerta o ventana, mostrar dónde está su amo a la amiga, darle el pie, tener la escala. Pero en esto se requiere en el criado que de no hacerlo se le haya de recrecer aun más grave daño, porque escalar casa ajena es injuria que le hace al dueño contra justicia ${ }^{47}$.
\end{abstract}

El prescindir de un personaje salvador es cerrar las puertas a una redención que, de nuevo, no depende de la petición final de confesión. Ausente la justicia clerical, la secular no parece interesada en abordar el caso de un noble moralmente díscolo. Esta ley civil puede legitimar acciones inequívocamente erróneas una y otra vez, como de hecho ocurre con los personajes de El burlador de Sevilla, tan fallidos en su comportamiento como el protagonista: las mujeres se entregan en matrimonios de palabra, el criado decide subyugar su voluntad, la familia de Don Juan encubre sus acciones, los padres casan a las hijas contra sus deseos, el rey distribuye matrimonios inconsultamente por propia conveniencia, y hasta las almas se declaran traidoras desde el más allá. Joan Ramón Resina ha interpretado el lenguaje de Don Juan como un nominalismo indicador de que «Tirso's play points to the limits of discourse and implies the need for a new linguistic order $»^{48}$, de modo que la estructura social tradicional está apoyada en la obra por los valores aristocráticos. Pero también coexisten los valores de una casuística subyacente que aparece en forma de no menos que cuatro matrimonios secretos, casamientos múltiples concertados por el rey, una nulidad matrimonial sugerida, un criado que somete incondicionalmente su voluntad para convertirse en cómplice de crímenes y el retorno de un alma en gracia para cometer una traición. A nuestro modo de ver, los personajes de esta obra se revelan como los mejores discípulos de Pascal al aprovechar los recursos que les ofrece la casuística. Si ello se interpreta como un deseo del autor por un nuevo orden moral o al menos un orden más claro, sin subterfugios, se explicaría la sorprendente ausencia de mediador espiritual, que requiere de la intervención directa de la divinidad. Los crímenes

${ }^{47}$ Antonio Escobar y Mendoza, Examen y práctica de confesores y penitentes, en todas las materias de la teología moral, Valladolid, María de Quiñones, 1650, p. 21.

48 «What Sort of Wedding? The Orders of Discourse in El Burlador de Sevilla», en Modern Language Quarterly: A Journal of Literary History 57, 4, diciembre 1996, p. 559. 
de Don Juan son perfectamente exonerables con argumentos casuísticos y, sin embargo, todo el mundo reconoce la «maldad» intrínseca de sus acciones, para cuyo castigo no son suficientes los medios de que dispone la Iglesia, como explica Edmund Leites:

There is no law, Hobbes and Locke said, unless there is a law-giver capable of punishing those who disobey him. This is just the power which the courts possessed and the casuists lacked. It was, of course, true that God could punish those who did not live according to divine law, but the casuist had no such means at his disposal. The authority of courts of law survived the rise in popularity because their capacity to inflict pain was so central to their power ${ }^{49}$.

Tirso aprovecha de ese modo los recursos escénicos y las ventajas de la ficción literaria para aplicar un castigo ejemplar que, como veremos, no resulta de la aplicación de un criterio de justicia poética y sí de las leyes compensatorias que rigen en el catolicismo.

«Ya sabéis lo que pasa cuando a algún desdichado dan una estocada sin que haya lugar de decir “¡Dios, valme!”». Esta formulaica frase de Francisco de Luque Fajardo expresa lo que todo católico sabe desde su primera instrucción catequística ${ }^{50}$. En el caso de Don Juan, la petición de confesión in extremis puede interpretarse como síntoma de conversión, como atrición, como recurso con el que cuenta por lo que sabe de doctrina católica, o como puro afán de presunción, caso que también recogen las sumas y que se adapta muy bien al carácter del personaje protagonista ${ }^{51}$. La crítica se ha afanado en determinar asuntos tales como el tránsito del alma en gracia de Don Gonzalo al espacio infernal y su posible retorno al cielo: «Nor there is any indication that Don Gonzalo, having delivered his charge into hell, will himself be obliged to stay there» ${ }^{52}$. Por desgracia, la casuística no ha regulado la comisión de encargos y crímenes de las almas de ultratumba, por lo que no podemos ofrecer una respuesta remotamente aproximada a esta circunstancia ${ }^{53}$. Sí es posible, en cambio, acercarnos a la actitud de Don Juan en sus momentos finales para definirla como un grave caso de atrición, acto

49 «Casuistry and Character», en Conscience and Casuistry in Early Modern Europe, Cambridge, MA, Cambridge University Press, 1988, p. 129. 1603.

${ }^{50}$ Fiel desengaño contra la ociosidad y los juegos, Madrid, Miguel Serrano de Vargas,

${ }^{51}$ « $\mathrm{Si}$ es circunstancia que haya necesariamente de confesar, el confesarse uno por vanagloria. No, porque la confesión hecha es provechosa, a no ser que fuera la última confesión, porque entonces no tendría propósito de enmienda y moriría en pecado» (Alonso de la VEGA, op. cit., lib. III, caso 292).

${ }^{52}$ Daniel Rogers, art. cit., p. 144.

${ }^{53}$ Sobre el tránsito de cuerpos y almas al más allá refiere jocosamente Jerónimo de Barrionuevo el suceso de un franciscano que apareció ahorcado y se oyeron voces que decían: «Quítenle el hábito, que nos queremos llevar el cuerpo al infierno, ya que tenemos allá el alma» (Avisos (1654-1658), edic. de Antonio Paz y Melia, Madrid, Biblioteca de Autores Españoles, 1969, 2 t., 14 de junio de 1565). 
que se reconoce desde el siglo XIII y representa una solución a la falta de contrición que permite liberar al fiel de los correspondientes castigos temporales $^{54}$ y, según Lutero, alejarlo del verdadero arrepentimiento. Don Juan sufre, tras haber sentido las penas del infierno de la mano de Don Gonzalo, una reacción atrita causada por el miedo (v. 2780-81), diferente de la contrición o arrepentimiento por dolor verdadero ${ }^{55}$.

Puede decirse que no hay en el Siglo de Oro un personaje menos atormentado por su conciencia que Don Juan Tenorio, de tal modo que podría llegar a pensarse que es un individuo nacido sin ella. Esta posibilidad ya fue explorada por Antonio Porras en los años cincuenta: «La conciencia de Don Juan está tranquila, no porque no tenga conciencia, como dice la gente del desaprensivo, sino porque él se pone frente a una moral con otra [...] no cabe duda de que en nuestro caso estamos ante una conciencia errónea siquiera sea sólo por contraria a la que determina el punto de vista católico reinante [...] padece una ignorancia que el moralista calificará de afectada o de supina» (120-121). Como esa conciencia errónea es vencible, dice Antonio Porras, infringe los preceptos de la doctrina católica, constituyéndose entonces en pecado sobre pecado. Dos décadas más tarde un artículo de Archimede Marni volvía a incidir sobre el asunto, proponiendo una definición distinta: «Transferring this to the case of Don Juan, it follows that if it may be proved that Fr. Gabriel Téllez looked upon him as a desalmado, as one already in Hell, then no deceit could have been involved in the oft-quoted "dame esa mano" ${ }^{56}$. Tras estas dos incursiones sólo se han producido breves atisbos críticos es esta dirección, que es interesante explorar. Ambas propuestas coinciden en la existencia de alma y, efectivamente, la Iglesia no reconoce como ser racional a alguien que haya nacido sin ella. «Desalmado», por tanto, debe entenderse en el sentido que le da Gonzalo Correas: «el de poca conciencia, que no mira por su alma». Don Juan no es el equivalente humano de Satán, pero tiene rasgos luciferinos que le aproximan a un ente sin alma (desaparición veloz, nocturnidad, ser innombrable, etc.), así como una cierta condición que le impulsa a la burla y le convierte en «castigo» y «langosta de las mujeres» (vv. 896 y 1472 , respectivamente $)^{57}$. Pero él mismo reconoce la existencia del alma:

\footnotetext{
${ }^{54}$ Faltaba por expiar las penas divinas ya que, como refiere James Atkinson, las indulgencias no podían sobrepasar el 1.902 .202 años y 270 días (Lutero y el nacimiento del protestantismo, Madrid, Alianza Editorial, 1980, p. 160, n. 1).

55 «Atrición es una contrición imperfecta, un dolor imperfecto; y esta imperfección es acerca del fin, porque el fin que le mueve al hombre a estar contrito es principalmente por temor de Dios, y menos principalmente por su amor divino» (Alonso de VASCONES, op. cit., p. 40).

56 «Did Tirso Employ Counterpassion in his Burlador de Sevilla?», en Hispanic Review 20, 2, abril 1952, p. 127.

${ }^{57}$ Para una descripción pormenorizada de estos y otros rasgos es de especial relevancia el estudio de Aurora EGIDO, «Sobre la demonología de los burladores. (De Tirso
} 
«Si un cuerpo con alma noble, / con potencias y razón, / y con ira, no se teme, / ¿quién cuerpos muertos temió?» (v. 2535-38), e incluso la convierte en mercaduría de corral que se vende al fiado. Partiendo de una tradición de emplazados, el personaje sufre un desplazamiento al universo contable donde el alma es objeto de donación literal por parte de un Don Juan ligero en regalarla: «El alma mía / entre los brazos te ofrezco» (v. 211314).

El alma al fiado y como método de pago, más patente en la tradición del pacto con el diablo, encuentra aquí nuevos visos que es necesario matizar. En el catolicismo se considera una cierta predestinación encarnada en un «determinado número de elegidos, con los que se va a empeñar en hacer gala de sus bondades y misericordia [...] Los elementos dogmáticos, dentro de la doctrina católica, son: la existencia de la libertad bajo el influjo de cualquier gracia, la existencia de la predestinación de los elegidos para el cielo y la existencia de la reprobación por la falta de correspondencia humana a las gracias divinas que todos reciben ${ }^{58}$. Reconocer que el Don Juan de Tirso carece de alma no es sólo teológicamente imposible, sino que lo convertiría en un personaje trágico, predestinado o «elegido» para el mal, desprovisto de libre albedrío y por tanto víctima de sí mismo o fastuosamente calvinista. A pesar de su «condición» o cierta predisposición a la burla la obra muestra varias oportunidades a través de las que Don Juan podría haber sido capaz de decidir su redención, adscribiéndose Tirso a la estela de otros malhechores literarios que encuentran la salvación al final de sus vidas ${ }^{59}$. Los pecados de Don Juan podrían haber sido perdonados por un sacerdote, cuya ausencia a lo largo de la obra es notoria; el protagonista podría haberse casado o sufrir la pena de hoguera por sus crímenes. En cambio, permanece impenitente al no reconocer sus culpas como tales hasta que el fuego de la justicia queda sustituido por las llamas del infierno.

Al final de la cadena de sucesos escenificados e intuidos hemos de sospechar que Don Juan no se condena por valentón ${ }^{60}$, ni por confiado $^{61}$,

a Zorrilla)», en El mito de Don Juan. Cuadernos de Teatro Clásico 2, 1988, especialmente las pp. 48 y 49.

${ }^{58}$ José M. $^{a}$ Delgado Varela, art. cit., p. 358.

${ }^{59}$ Encontramos casos de esta tradición en El rufián dichoso de Cervantes, La devoción del rosario de Lope, El esclavo del Demonio de Mira de Amescua, el Enrico del tirsiano El condenado por desconfiado e incluso el mismísimo Roberto el diablo.

${ }^{60}$ «Sigue ignorando que el verdadero valor estriba en un justo conocimiento del peligro que impide pecar de temerario o de temeroso. No es valiente sino valentón, o sea física y moralmente cobarde» (Marc VITSE, «Don Juan o temor y temeridad. Algunas observaciones más sobre «El burlador de Sevilla»», en Cahiers du Monde Hispanique et Luso-Brésilien 13, 1969, p. 74.

${ }^{61}$ Michel Aubrun, «Le «Don Juan» de Tirso de Molina. Essai d'interprétation», en Bulletin Hispanique 49, 1957, p. 45. 
ni tan siquiera por abusar de la casuística, aunque la utilización del sistema en su propio beneficio revela una crisis de la que Tirso era consciente. Su castigo está más allá de la aplicación de una simple regla de justicia poética y su entusiasmo pecador se traduce, según entendemos, en otra esfera de la conciencia que no niega ninguna de los adjetivos mencionados, sino que los agrupa a todos. Existe una posibilidad más acorde con las características del personaje, identificada por el catolicismo en el contexto áureo y aplicable a individuos instruidos en la fe. En su elaborado tratado sobre los ateos y sus calidades, fray Jerónimo Gracián de la Madre de Dios establece una categoría que agrupa a los «Ateístas Cristianos desalmados, que siguen y profesan la fe y ley de Cristo Jesús, y en ella están bautizados, pero viven de tal manera, y están tan endurecidos, insensibles y obstinados en sus pecados y vicios, que dicen en su corazón no haber Dios: y viven, como si no le hubiese» ${ }^{62}$. En la «lamentación octava», el carmelita especifica que este género de ateos, muy a pesar de ser cristianos, se comportan como obstinados, insensibles y duros de corazón, describiendo fray Jerónimo Gracián tres estadios, el último de los cuales, el más avanzado, corresponde con pasmosa exactitud al perfil de Don Juan Tenorio: «unos principiantes, que comienzan el camino del pecado, otros, que van creciendo y deteniéndose en él, y los terceros, a quien podemos llamar desalmados, obstinados, y endurecidos». Los atributos que conviven en estos seres se hacen patentes en las diferentes facetas que conforman el comportamiento de Don Juan. Como se comprueba en el homicidio de Don Gonzalo y en el lance con Don Pedro, «tienen pies ligeros para derramar sangre por los odios, rencores, enemistades, y poca paz con que viven entre sí. Porque como faltan en la caridad de Dios, también faltan en el amor del prójimo. Y así cuando se les ofrecen venganzas, ejecutan sus malas voluntades y no ponen freno en la ira». Se definen, además, como seres injuriosos que sistemáticamente deshonran al prójimo: «Las malas lenguas de estos desalmados, no se pueden explicar con pocas palabras. Porque (demás de las mentiras, juramentos, blasfemias y murmuraciones que dicen) con los falsos testimonios que levantan a otros, haciéndoles mal con la lengua, con que les quitan la honra [...] nunca restituyen honra que quitan, ni hacen caso de la quitar: y como gente sin Dios, se endurecen cada día más en su abominación de mala lengua».

Más importante todavía es la falsa valentía, que las Diez lamentaciones definen como

la falta del temor es el principal seminario del Ateísmo. Esta falta se halla en muchos desalmados Católicos, que ni temen a Dios, ni a su divino juicio, ni a la muerte, infierno, purgatorio, ni aun temen de perder su vida, honra y

${ }^{62}$ Diez lamentaciones del lamentable estado de los ateístas de nuestro tiempo [1611], en Beatus vir: Carne de Hoguera, edic., intr. y n. de Emilia Navarro de Kelley, Madrid, Editora Nacional, 1978, pp. 270-361. 
hacienda, por no dejar de hacer su voluntad, cuando se les ofrece la ocasión: y así como faltos de temor (aunque están bautizados) les falta la sabiduría, la gracia, y Dios del corazón, y vienen a ser Ateístas.

En conclusión, los actos del ateo desalmado reflejan la negación de Dios y son más perjudiciales que los herejes políticos, «porque vive de tal manera, y hace tales obras, como si no hubiese Dios [...] pero faltándole en el corazón el aceite de la caridad, cuando a la hora de la muerte pensare que ha de entrar en el cielo, le darán con la puerta en los ojos, y le dirán, que no le conocen ${ }^{63}$.

El descreimiento de Don Juan, salvadas las citadas excepciones, no ha sido considerado en la tradición crítica sobre El burlador de Sevilla. El propio Américo Castro sostuvo que «Don Juan cree en Dios porque el patio no habría tolerado discusiones sobre la divinidad, ni a Tirso podrían ocurrírsele» ${ }^{64}$, cuando el desarrollo escénico de un personaje ateo no significa poner en tela de juicio la existencia de la divinidad sino, como ocurre en esta obra, reafirmarla. En la misma línea se expresó Jöel J. Saugnieux al declarar que «La condenación de Don Juan marca, pues, el retorno a una ortodoxia [...] Satisface a la vez las exigencias de toda sociedad para la que la existencia de la Moral es una necesidad vital, y las de la tradición católica, turbadas por un instante (si no amenazadas) por las audaces conclusiones del Condenado [...] Don Juan será condenado a pesar de su fe en Dios, que es sincera a despecho de las apariencias» ${ }^{65}$. Muy al contrario, las acciones y palabras de Don Juan revelan una falsa fe basada en la estirpe familiar que no se corresponde con la de un creyente. Cautamente lo expresó Francisco Márquez Villanueva, quien supo aproximarse muy de cerca al estado del alma donjuanesca, incapaz de reconocer su culpa:

Santo Tomás se atiene a las palabras de San Agustín para considerar blasfemia contra el Espíritu Santo la impenitencia que procede lo mismo de desesperación o de presunción, en cuanto modalidades gemelas de un pecado contra la fe $[\ldots]$ es obvio que no se trata de descreimiento sino de menosprecio de Dios [...] La insensatez voluntaria y pertinaz de Don Juan constituye un pecado de extrema gravedad. Como tal lo razonaba en 1563 el dominico fray

${ }^{63}$ Es reacción común en el ateísta desalmado el miedo ante la muerte en sus instantes finales: «que por animoso que sea un hombre, forzosamente ha de temer las cosas de la otra vida, y verificarse esta verdad en el suceso de aquel mal rey Baltasar, tan desalmado, sin razón ni término, que perdiendo el respeto a Dios, en sus fiestas y convites se servía con los vasos del templo dedicados al divino culto; y porque sólo vio escribir unas letras en la pared de la sala donde estaba, dice el sagrado texto que del temor que recibió se le desencajaron los huesos» (Jerónimo ALCALÁ YÁÑEZ Y RIBERA, Segunda parte de Alonso mozo de muchos amos, Valladolid, Jerónimo Morillo, 1626, p. 553).

${ }^{64}$ Ed. cit., p. XXIII.

65 Art. cit., p. 218. 
Juan López en la historia paralela en sentido contrario de Cristóbal de la Cruz, fuente y modelo de El rufián dichoso de Cervantes ${ }^{66}$.

El burlador de Sevilla marca la primera aparición de un ateo desalmado en la escena española. Don Juan, incapaz de identificar el infierno como un espacio de expiación eterna, lo describe como «temores extraños» (v. 1996), y se encomienda a las estrellas para pedir suerte en sus lances (v. 1928). Es por ello que la iglesia no puede ser un espacio de inmunidad eclesiástica sino de condenación, la puerta abierta al infierno hacia donde transitará el alma de un ateo tras desplegar sus artes de mal morir.

El tema del ateísmo en la España áurea ronda los escritos de la omnipresente institucionalización religiosa, que reconoce la existencia de focos de descreimiento en legajos inquisitoriales, como indica Barbara A. Simerka en su interesante panorama europeo ${ }^{67}$. Pero, a diferencia de lo que propone la autora, no es necesario adoptar ninguna estrategia particular para leer entre líneas, puesto que el perfil del ateísta desalmado está documentado en el propio contexto histórico de El burlador de Sevilla. Es, por tanto, legítimo reconocer que Don Juan es un desalmado en su máximo desarrollo conforme a los parámetros propuestos en las Diez lamentaciones, y creemos haber dado suficientes pruebas para vencer la resistencia crítica y desdecir de una vez que la fe del protagonista es sincera y que «Of course, the Spanish Don Juan never disavows Christianity» ${ }^{68}$. No es casual que tanto el Don Juan de Molière (1665) como el Libertin de Shadwell (1677) apunten en esta dirección, mucho más que sugerida por el de Tirso de Molina: «Don Juan est simplement athée chez Molière et libertin au XVIII ${ }^{e}$ siècle» ${ }^{69}$. Don Juan Tenorio, ateísta desalmado por voluntad propia, encaja en el perfil de estos individuos que el Critilo gracianesco tenía la facultad de distinguir con sólo mirarlos: «Yo veo, yo conozco si uno tiene alma o no. - Pues ¿hay quien no la tenga? - Sí, y muchos, y por varios modos. - ¿Y cómo viven? - En diptongo de vida y muerte» ${ }^{70}$.

Por el momento no se han establecido los hilos del ateísmo en la historia de la literatura áurea española, si bien son inestimables a este fin los apuntes de Julio Caro Baroja, quien identifica conductas propias de los sin Dios desde el pensamiento presocrático en adelante, poniendo de manifies-

66 Op. cit. pp. 168-169.

67 «Eros and Atheism: Providential Ideology in the Don Juan Plays of Tirso de Molina and Thomas Shadwell», en Echoes and Inscriptions: Comparative Approaches to Early Modern Spanish Literatures, edic. de Barbara A. Simerka y Christopher B. Weimer, Lewisburg, PA, Bucknell University Press, 2000, pp. 222-224.

68 Barbara A. SIMERKA, art. cit., p. 225.

${ }^{69}$ Michel Aubrun, art. cit., p. 41, n. 31.

70 Baltasar GRACIÁn, El Criticón, tercera parte. En el invierno de la vejez [1657], edic. de Miguel Romera-Navarro, Filadelfia, University of Pennsylvannia Press, 1940, p. 159. 
to la conexión entre un rito pulcro y una creencia dudosa - lo que ampliaría considerablemente el número de ateos acogidos en el seno de la Iglesia-, además de rastrear la presencia de tales seres en la obra de Cervantes, Lope de Vega y, sobre todo, Quevedo y Calderón de la Barca ${ }^{71}$. Asomándonos un poco más allá, el caso del Don Juan tirsiano, germen que con el andar del tiempo derivará en el libertino decimonónico, encuentra manifestaciones contemporáneas a esta comedia en el ateo político encarnado en la pluma de Juan Blázquez Mayoralgo ${ }^{72}$. También en la quevediana «Providencia de Dios», que en 1641 prueba irrefutablemente a los ateos la existencia divina, más fácil de demostrar que su ausencia, y en la mejor difundida Confessio naturae contra atheistas que Gottfried Leibniz publicara en 1668. Entre los descreídos documentados históricamente se encuentra la figura señera del aristotelista Lucilio Vanini todavía recordada por Benito J. Feijoo en 1728, «que por tal fue quemado en Tolosa de Francia el año de $1609 »^{73}$, y el hoy célebre pero entonces igualmente infame para católicos y calvinistas Miguel Servet (1511-1553), quien sobrevivió dos años a su muerte en efigie tras esbozar el sistema de circulación de la sangre. Tirso, que en otras comedias prefirió la intervención providencial de ángeles indultores, opta por servirse de las llamas de un infierno que tanto conviene a los ateos desalmados. Tal vez una elaboración pormenorizada del tema en sus vertientes histórica y literaria nos permitiría saber si la imagen de Don Juan se refleja en el espejo Barroco.

${ }^{71}$ De la superstición al ateísmo (Meditaciones antropológicas), Madrid, Taurus, 1974, pp. 257 y ss.

${ }^{72}$ Perfecta razón de estado. Deducida de los hechos del señor rey don Fernando el católico, quinto de este nombre en Castilla, y segundo en Aragón. Contra los políticos ateístas, México, Francisco Robledo, 1646.

${ }^{73}$ Teatro Crítico Universal. Discursos varios en todo género de materias, para desengaño de errores comunes, Madrid, Joaquín Ibarra, 1728, t. II, disc. I, «Guerras filosóficas», § III, 26. En realidad Vanini fue ejecutado en 1619 por intuir la teoría de la evolución humana. 